FiA $M$ S

\title{
Self-Healing Materials: What Can Nature Teach Us?
}

\begin{tabular}{|r|l|}
\hline Journal: & Fatigue \& Fracture of Engineering Materials \& Structures \\
\hline Manuscript ID & FFEMS-6643.R1 \\
\hline Manuscript Type: & Invited Contribution \\
\hline Date Submitted by the Author: & n/a \\
\hline Complete List of Authors: & $\begin{array}{l}\text { Dooley, Clodagh; Trinity College Dublin, Advanced Microscopy Laboratory } \\
\text { Taylor, David; Trinity College Dublin, Mechanical Engineering }\end{array}$ \\
\hline Keywords: & Fracture, Fatigue, Damage, Fatigue damage repair, Toughness \\
\hline &
\end{tabular}

SCHOLARONE ${ }^{m}$

Manuscripts 


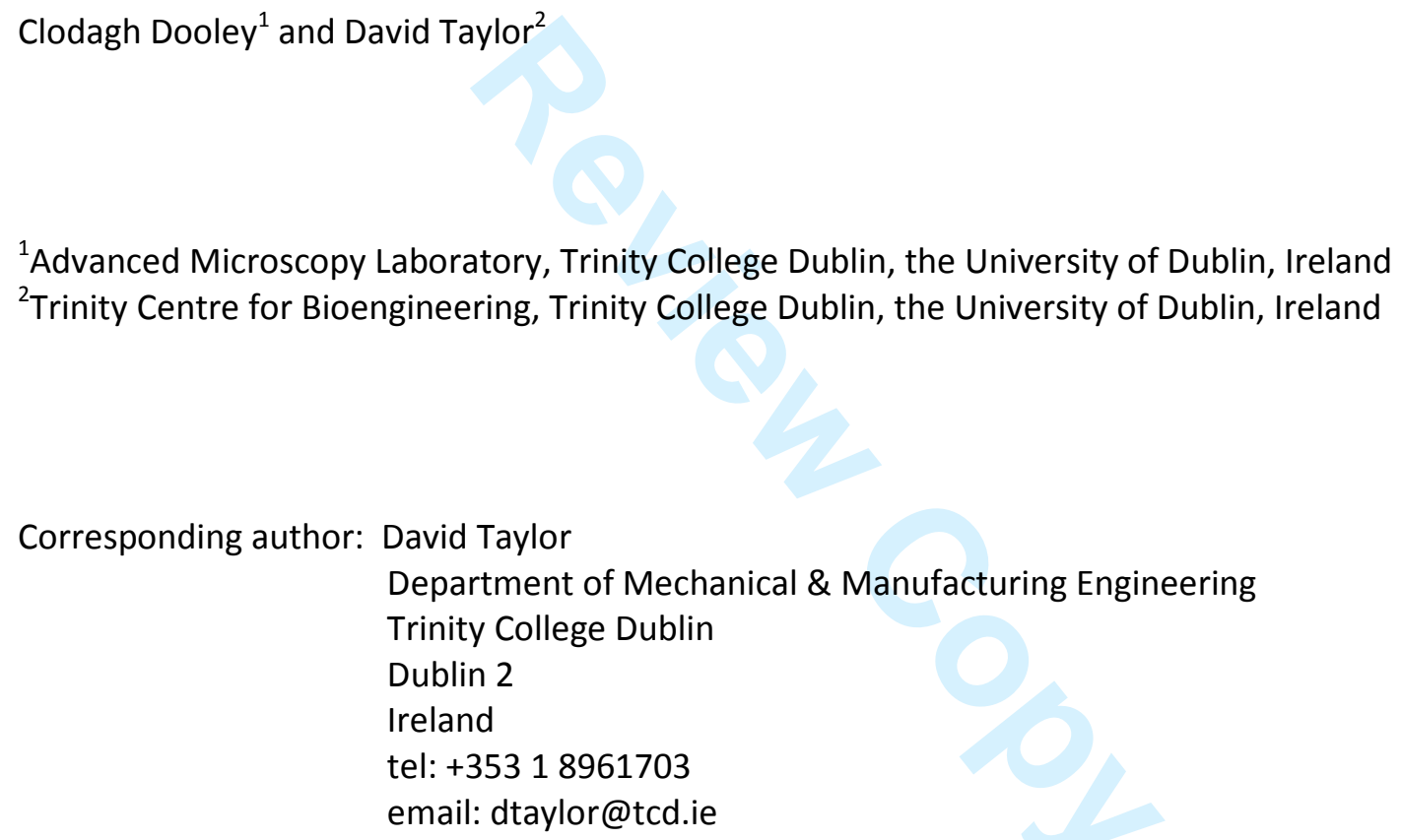




\section{Abstract}

Natural materials such as bone and insect cuticle are capable of self-repair, a facility which greatly increases their durability and safe working stress. Some engineering materials have also been designed to be self-healing, though currently they cannot match the performance of natural materials as regards the efficiency and longevity of the healing process. In this article we review the state of the art regarding these two types of materials. We discuss the role of fracture mechanics in the development of theoretical models of self-healing, we identify certain crucial parameters which make natural materials successful and discuss how these lessons can be applied to improve the performance of self-healing materials for engineering applications.

Keywords: Self-healing materials; strength; toughness; fatigue; damage; repair

\section{Introduction}

This review is concerned with the phenomenon of self-healing, a topic which is of interest to biologists and also to engineers, and especially to those working in the interdisciplinary field of biomimetics. Biomimetics is an approach to engineering design which starts from Nature. By examining biological structures and materials, in animals and plants, we can learn useful lessons and seek inspiration for novel engineering solutions. This approach has had some notable successes: arguably we would not have developed heavier-than-air flying machines had we not been inspired by birds. Today there is a large literature on this subject and many practical examples of bio-inspired designs (e.g. ${ }^{1}$ ), several university courses on the subject (e.g. Biomimetic Principles and Design at MIT) and a number of specialist journals (e.g. Bioinspiration and Biomimetics).

How useful has biomimetics been in the field of fracture mechanics and structural integrity? What can we learn from Nature about the performance of load-bearing materials? Many biological materials are required to withstand high forces, giving rise to stresses of the order of tens, and occasionally hundreds, of $\mathrm{MPa}^{2,3}$. But it's fair to say that modern engineering materials have better mechanical properties than those found in Nature ${ }^{4}$. There is no material in the natural world which matches the toughness of metals, and we can make polymers, fibre composites and ceramics with better strength/weight and stiffness/weight ratios than the equivalent biological materials such as tendon, bone, arthropod cuticle, plant stems or mollusc shells.

Nevertheless Nature does have a lot to teach us in this field. In particular, there are two features which have drawn attention and which are the subject of much research and development. The first of these is the ability of biological materials to develop improved toughness as a result of their complex microstructure and nanostructure. We use the phrase "improved toughness" here rather than "high toughness" because in an absolute sense, materials such as human bone and nacre (part of the structure of the abalone seashell) are not particularly tough; they both have fracture toughness $\mathrm{K}_{c}$ values of the order of $4 \mathrm{MPaVm}$. What is interesting about these materials is that they are made from constituents which have toughness values about ten times smaller than this. Nacre, and other materials found in the shells of sea creatures (e.g. mussel, limpet, conch) is almost a pure ceramic, calcium carbonate, with just a few percent of organic material and water. The $\mathrm{K}_{\mathrm{c}}$ value of this material in bulk mineral form is about $0.3 \mathrm{MPaVm}$ and a similar value can be measured in eggshell ${ }^{5}$ which has a very simple microstructure. The more complex microstructure of nacre, which is made up of tile-like units at the micron scale with specially-developed interfaces ${ }^{6}$, confers additional toughness through crack deflection and several other toughening mechanisms which are currently the subject of much research. 
Likewise the multi-level, hierarchical structure of bone enhances toughness: mechanisms include crack deflection and crack-bridging ligaments ${ }^{7,8}$. Through studying these materials, researchers have developed engineering ceramics and composites with enhanced toughness, which are showing great promise (e.g. ${ }^{9}$ ).

The second feature of natural materials which arouses interest is their self-healing ability, and it is this attribute which is the subject of the present article. We are all familiar with the idea that our body parts can heal if broken or damaged: what is perhaps not so well appreciated is that many of our load-bearing tissues such as bone and skin are subject to a process of continuous healing at the microscopic scale, which acts very effectively to prevent long-term failure modes, especially fatigue, and thus extend the useful life of the material almost indefinitely. Despite considerable research, the exact mechanisms by which this is achieved are still not completely understood, but several useful insights have emerged in recent years, which will be discussed in detail below.

In parallel with this effort, many researchers are working to develop engineering materials with selfhealing capabilities. We can define a self-healing material, without too much loss of generality, as a material which, whilst experiencing a failure mode that involves crack initiation and growth (i.e. fatigue, stress-corrosion cracking, creep or brittle fracture) is capable of removing or reducing sub-critical cracks and thus extending its lifespan and increasing its safe working stress. This field has a long history and the volume of new work and new materials emerging has accelerated very much in recent times. It is surprising, therefore, that the amount of this work which is reported in the fracture mechanics journals is very small. A recent search of all the major journals in this field (Fatigue and Fracture of Engineering Materials and Structures, Engineering Fracture Mechanics, Theoretical and Applied Fracture Mechanics and the International Journal of Fatigue) using keywords "heal" and "healing", produced only 30 relevant publications for the entire history of these four journals. This implies that, though many novel and interesting materials are being developed, their development may benefit from more understanding and application of advanced fracture mechanics concepts.

In this article we review the current state of knowledge regarding self-repair in biological materials, especially at the microscopic scale, and the various approaches which have been used to create selfhealing materials for engineering purposes. We also review the use of fracture mechanics concepts to understand and model the behaviour of both of these groups of materials. Finally, we conclude by considering the opportunities for biomimetics: can we be inspired by Nature's solutions to create better, longer-lasting materials through self-healing?

\section{Self-repair in endoskeletons and exoskeletons}

Many of us are familiar with the experience of breaking a long bone, such as an arm or leg bone, and we all know that, even if a complete separation occurs, the body can repair the fracture if the two halves of the broken bone are put back in alignment with the broken ends in good contact. This is generally something that requires medical assistance and so doesn't happen in the natural world. A better example of a natural repair would be a bone such as a rib, which as a result of impact becomes cracked but not completely separated. After a few weeks the cracked area will be replaced by new bone in a carefully orchestrated process. The resulting material will be just as strong and tough as the original undamaged material. This process operates in very much the same way in other mammals, and indeed in all vertebrates, implying that it developed at a relatively early stage in our evolutionary history. It is a good example of an ideal self-healing material, at least in normal, healthy individuals with normal activity levels. 
But what about other animals, in particular those having exoskeletons? The arthropods are a large group of organisms which include insects and crustacea. A common feature of these animals is an external skeleton, which is made from a material different from that of the mammalian endoskeleton. This material is called cuticle and consists of fibres of chitin, a natural polymer, embedded in a matrix of proteins, water and, in some cases, ceramic particles. It has been known for some time that this material is capable of repair, but only recently has this been studied from a mechanical point of view. If a cut is made into the exoskeleton, for example the leg or body of an insect, then the immediate effect is leakage of blood, followed by a clotting reaction in which the blood becomes sufficiently viscous to seal the wound ${ }^{10}$. In this respect cuticle behaves very much like our skin, but unlike skin it does not have any living cells near its outer surface. Rather, there is a continuous layer of cells located on the inner surface of the skeleton. If this layer is breached, the cells will move to attempt to cover up the gap, and a series of biochemical reactions will be initiated, which result in new cuticle material being made and deposited in the area over the following days and weeks ${ }^{11,12}$. However this new material can only be made on the inner surface, not on the outer surface or within the cut itself. Figure 1 shows a fracture surface of part of the leg of a locust, which is essentially a hollow tube. This leg was tested by first making a transverse cut with a sharp knife, then leaving the insect for three weeks, and finally breaking the leg by applying a bending moment. The original cut surface is still plainly visible, showing that this was not repaired. New material formed underneath the cut, making a kind of patch across the damaged area. This new material can be seen to have fractured during the bending test. It was found that the repair process increased the strength of the damaged leg by about a factor of two, bringing it to about $66 \%$ of the strength of the original, intact leg ${ }^{13}$. The repair seems to rely mainly on the effect of the patch material to reduce the stress concentration effect of the cut, though it's also possible that the properties of the material itself may change.

Another large class of materials having exoskeletons are sea creatures such as molluscs. These have stiff, relatively strong shells made from calcium carbonate. A frequent cause of mechanical damage to these shells is high-speed impact as a result of moving rocks and other materials during storms ${ }^{14}$. Figure 2 shows examples of impact damage in limpet shells, which typically takes the form of cracks or holes. Several investigations have shown that this damage can be repaired ${ }^{15,16}$. Figure 2 also shows an example of the repair process, which is rather similar to that described above for arthropods, consisting of the formation of a patch of material below the original damaged area. To date there has been only one study to investigate the mechanics of this repair ${ }^{17}$ : shells were compressed to failure between platens; those shells showing evidence of repaired damage were found to be just as strong as normal, intact specimens.

Studies have shown, both for insects and for molluscs, that the patch forms only in the immediate vicinity of the damage ${ }^{13,15,16}$, thus being an efficient use of the available material. A common feature of repair in these different natural materials is that it is carried out and organised by living cells: our bones contain many such cells throughout the material, and we have learnt a lot about how these cells operate to heal fractures ${ }^{18}$; in the case of arthropods and molluscs the cells are only to be found on the inside surface. Nature teaches a clear lesson here which can be applied to the development of self-healing materials: the necessary sensors and actors must be appropriately located, ideally well distributed throughout the volume of material and sufficiently close together to be effective; this will be discussed in more detail below. 


\section{Repair of microdamage through remodelling}

In the 1960s, researchers discovered something rather surprising: our bones are full of microscopic cracks $^{19}$. Since then, we have discovered a number of interesting facts about these microcracks. They are found in large numbers in normal living bone: typically about 100 cracks per cubic centimetre. They exist throughout the bone volume, not preferentially on the surface. They are typically elliptical in shape, of average size $100 \mu \mathrm{m} \times 400 \mu \mathrm{m}^{20}$. Most interestingly, they are fatigue cracks, which form and grow as a result of cyclic loading ${ }^{21}$. However, unlike fatigue cracks in engineering materials, they rarely grow to exceed $1 \mathrm{~mm}$ in length, because they are constantly being repaired. The growth and repair of microdamage has been the subject of extensive research, the findings of which will be briefly summarised here (for more details the reader is referred to two review articles ${ }^{22,23}$ ). The repair process itself is carried out by the concerted action of two different types of cells: osteoclasts and osteoblasts. The osteoclasts are capable of dissolving bone by releasing a powerful acid, thus creating a small cavity (known as a BMU) inside the material. By concerted action of the osteoclasts and osteoblasts (cells which make new bone), this cavity moves through the bone, thus allowing for a continuous replacement process which occurs at a rate of about $0.5 \mathrm{~mm}^{3}$ per year per cavity. Studies of bone in living animals established that these cavities are attracted to areas containing microcracks, effecting repair by removing and replacing the damaged material ${ }^{24}$. The result of the repair of microcracks by a BMU is a newly remodelled area of bone known as a secondary osteon: figure 3 shows examples of the appearance of these features: for further examples the reader is referred to the literature ${ }^{25,26}$.

This process of microcrack repair by replacement of the surrounding material, which is often referred to as bone remodelling, is extremely effective in raising the fatigue strength of the material and therefore the cyclic stress at which it can be used. It has been estimated that if remodelling did not occur, then our bones would fail by fatigue cracking within approximately one year of normal life. Or, to put it another way, the existence of remodelling allows the material to be used at a stress which is about 3.5 times higher than would otherwise be possible ${ }^{27}$. This gives us a sense of the potential benefits to be achieved when self-healing is introduced into a material. The capacity to repair local damage also allows the material to respond efficiently to stress concentrations. For example, regions of bone close to a metal screw inserted as part of an orthopaedic operation develop increased numbers of microcracks, which are subsequently remodelled ${ }^{28}$.

A crucial parameter here is the length to which the microcrack grows before it is repaired. Measurements of large numbers of these cracks in normal healthy bone show a remarkable degree of consistency in their lengths, which are invariably of the order of $100 \mu \mathrm{m}$ when viewed on transverse sections. The microstructure is clearly responsible for this: secondary osteons, which exist at this scale (see fig.3b), act as barriers to crack growth ${ }^{29,30}$. Thus, as is also well known in metals and other materials, fatigue cracks grow relatively quickly until they meet these barriers, at which stage they pass through a minimum growth rate ${ }^{31}$. So if one were designing a repair process for this material, one would naturally choose it to operate around this length scale: operating at a larger scale would be risky because the cracks would then be growing much faster, but operating at a smaller scale would be a poor use of resources because one would be repairing many cracks which will never grow to cause failure. The BMU cavity is indeed of this scale, having a typical diameter of $200 \mu \mathrm{m}$.

\section{Detection of microdamage in bone}

Any self-healing process requires two features: detection and action. Damage must first be detected before the repair action can proceed. In the case of bone, the actors in the repair operation are 
osteoblasts and osteoclasts. But what about detection? Surprisingly, this feature has turned out to be more difficult to elucidate. There is a third type of cell commonly found in bone, known as the osteocyte, which has long been suspected of playing the role of the detector of microcracks. These cells are found in large numbers in normal healthy bone; they live in small cavities within the material and are linked together into three dimensional networks by long, narrow extensions known as cellular processes (see figure 3). Given the typical density of osteons in bone ${ }^{32}$, a typical separation distance between osteocytes is $37 \mu \mathrm{m}$, and each osteocyte has $50-100$ cellular processes ${ }^{33}$. Therefore if an elliptical crack size $100 \times 400 \mu \mathrm{m}$ was present, it would be likely to disrupt this network significantly, because there would be tens of osteocytes and hundreds of cellular processes in the immediate vicinity of the crack. If the resolution of this network is compromised, for example by loss of some of the osteocytes, which occurs during aging, or a reduction in the number of cellular processes per osteocyte ${ }^{34}$ then bone's ability to repair itself is reduced, leading to a loss of strength in the material ${ }^{26}$.

The response of the osteocyte network to microcracks, and its role as a detection system, has been studied both in vivo and in vitro. Kennedy and co-workers induced cracking in the bones of living rats and examined the osteocytes nearby ${ }^{35,36}$. They found that some of the cells close to the cracks underwent apoptosis (controlled cell death) whilst other cells nearby produced increased amounts of a substance known as RANKL (see figure 4). This is one of a series of molecules known as cytokines, which are responsible for passing signals from one cell to another. The RANKL cytokine acts as a signal to attract and stimulate osteoclasts, thus initiating the remodelling activities of the BMU. Another substance commonly secreted by cells, known as OPG, acts in opposition to RANKL and so tends to supress remodelling: in these experiments OPG was found to be reduced in the vicinity of the microcracks. We approached this problem in a different way, by culturing networks of osteocyte cells in vitro, and introducing damage into these networks. In our first experiment we were able to measure qualitatively similar changes (increased RANKL, reduced OPG) to those recorded by Kennedy et $a{ }^{37}$; we were also able to detect the early stages of the bone remodelling process itself, such as osteoclast activity and the production of calcium ${ }^{38}$. However these changes were not detectable for crack-like damage (i.e. narrow slots), but a practical limitation in those experiments was that we were not able to distinguish between the activities of cells close to the damaged area and those remote from it in other parts of the network. Recently we have remedied this deficiency by using a different method to measure cell signalling activity, using a technique which allowed the activity of individual cells to be visualised directly. Details of the methodology can be found in ${ }^{39}$. Briefly, networks of osteocyte-like MLO-Y4 cells were cultured in monolayers on glass plates. Damage was applied by scribing a line on the surface: lines of various thicknesses were used from 10-800 $\mu \mathrm{m}$. After some time the cells were fixed and different coloured fluorescent stains were applied to reveal apoptotic cells (cleaved caspase 3 stain) and either RANK L or OPG (antibody stains). Image analysis was used to record the amount of each coloured stain. The results are shown in figure 5: apoptosis, RANKL and OPG levels changed dramatically in the region close to the damage, demonstrating the ability of the osteocyte network to detect damage, including crack-like defects.

These results can be interpreted in a number of different ways. Some researchers have proposed that the effect of the microcrack is to alter the flow of fluid which passes through the holes and channels in the bone in which the osteocytes reside. This fluid contains essential nutrients to keep these cells alive, and also transports the signalling molecules. Others have suggested that the crack acts to physically disrupt the network of cells and cellular processes. Colopy et al found evidence of physical breaks in the network ${ }^{40}$. We observed cellular processes passing across between the faces of microcracks (see figure 6). By applying cyclic loading we showed that these processes failed by fatigue, and that the number of cycles needed to cause these failures was much less than that needed for fatigue failure of the bone 
itself ${ }^{41,42}$. Cells are known to be sensitive to mechanical strain ${ }^{43}$ and so might be able to detect changes in fluid flow by monitoring the fluid shear stress on their surfaces. Mechanical rupture of the cellular processes, which are part of the bodies of these cells, would also initiate chemical changes in the cell itself in response to this potential threat. A recent experiment showed that networks of osteocytes in vitro responded to both physical damage and fluid shear stress ${ }^{44}$. It seems clear that the osteocyte network is acting as a mechanical transducer, sensitive to local changes caused by the presence of microcracks. But further work is needed to understand some of the details: an important clue obtained from the in vivo work is that apoptosis of some of the cells is an essential step: when this was suppressed, none of the other local changes occurred ${ }^{36}$. The bone matrix itself may play a role: a recent experiment by Shu et al bridges the gap between our work and that of Kennedy et al: they grew cells in vitro on the surface of a sample of hydroxyapatite (the mineral phase of bone). They found that introducing microcracks into the mineral enhanced osteoblast activity, possibly because those cells were sensing the calcium released during cracking ${ }^{45}$. Further clues as to how this calcium release might stimulate altered cell behaviour come from recent in vitro work on notched bone samples ${ }^{46}$.

It seems clear that the osteocyte network is acting as a mechanical transducer, sensitive to local changes caused by the presence of microcracks. Crucially, from the fracture mechanics point of view, the scale of this operation, dictated by the separation of osteocytes and their cellular processes, is ideal for detecting cracks of size $100 \mu \mathrm{m}$ which, as mentioned above, is the most appropriate and efficient scale for the repair of fatigue damage in this particular material.

\section{Strategies for self-healing engineering materials}

Long before self-healing materials were being deliberately designed and developed, some engineering materials already had this capacity. Cracks in cements have been healing themselves ever since these materials were first used, over two thousand years ago, thanks to reactions with atmospheric water and $\mathrm{CO}_{2}$, producing more cementitious material to fill the cracks ${ }^{47}$. In bituminous materials, surface cracks caused (for example) by the passage of vehicles over a road surface, tend to heal up automatically thanks to the tendency of the binder phase to creep and flow ${ }^{48}$. The same phenomenon occurs in metals at sufficiently high temperatures, when a combination of creep and applied compressive stress can cause healing by a sintering reaction. There is an obvious disadvantage of this approach: if the material is being used in a regime of stress and temperature where creep is occurring, then its lifetime is likely to be strictly limited anyway; if the material is being used at a lower temperature, then the healing can only be achieved by periodic phases of heating.

This brings us to an important distinction: there are essentially two different types of self-healing materials: those which continuously repair damage during normal operation and those for which the healing occurs separately, during a period in which special conditions are applied. The latter approach includes, for example, the application of high-density electric currents to metallic materials which has been found to be effective in healing fatigue damage ${ }^{49}$. High-performance engineering ceramics have also been developed with self-healing capabilities, using essentially the same strategies as for cementitious materials: cracks expose material to the environment, causing reactions (usually oxidation) in one of the phases present, creating more solid material to fill the crack and bind to the surrounding matrix. A wide range of such materials have been developed (e.g. $\left.{ }^{50,51}\right)$; in most cases the reactions only occur on heating to relatively high temperatures, above the normal working temperature of the material. These approaches are certainly very interesting and have potential for incorporation into maintenance procedures for engineering components. However, strategies which allow continuous selfhealing are potentially more powerful because damage can be repaired when it is still very small, and 
normal operations do not have to be interrupted. One recent example in the field of metallic materials is the use of gold in ferrous alloys, which inhibits damage by forming precipitates on dislocations and other deformation-induced defects, as shown in figure $7^{52}$.

The class of materials in which continuous self-healing has been most comprehensively developed is polymers, including polymer-matrix composites. Polymer systems which continuously self-heal are generally referred to as "extrinsic" systems, because they contain a specific additive in the form of, for example, microcapsules. By contrast, "intrinsic" self-repairing systems contain no such additives but require special imposed conditions such as heating or an altered chemical environment, usually to stimulate a reversible polymerisation reaction. An example of a typical extrinsic system is an epoxy resin which can be healed by incorporating two agents: a monomer (for example dicyclopentadiene) and a catalyst which allows the monomer to polymerise at room temperature. The monomer is incorporated in microscopic hollow spheres made, for example, from wax. The catalyst may also be introduced in microspheres, or may be spread uniformly throughout the polymer. Such approaches have been developed to a high level of sophistication and have been shown to be capable of restoring the strength of damaged material to values close to that of the original, undamaged state (see for example ${ }^{53,54}$ ). Figure 8 shows the general principle and an example of the healing process in action. However these systems have a significant drawback which is that the healing mechanism can only operate a single time: once the capsules have been ruptured and the reaction carried out, the material is no longer self-healing in that particular location.

\section{Theoretical modelling}

Modelling approaches which have been previously developed for non-repairing materials can be modified to include self-repair, but this development is not without its challenges. The approach which is perhaps most easily adapted to take account of healing in materials is continuum damage mechanics (CDM). In CDM, damage is represented by a single quantity (usually a scalar but in some cases a tensor to allow for anisotropy) which varies from zero in virgin material to unity at failure. The approach is popular in predicting lifetimes where the failure mechanism is complex or where multiple input parameters are involved. Examples are creep failure under varying stress and/or temperature conditions, or fatigue failure under variable-amplitude loading. It is a relatively straightforward matter to include healing in CDM as a negative rate of damage accumulation. This was done, for example, to assess the potential of fatigue failure occurring at a stress concentration such as a hole introduced into a bone during surgery ${ }^{55}$. Fatigue damage will develop near the hole at a rate dependant on the local cyclic stress. The effect of the body's natural repair systems was included in two ways: firstly as a constant rate of decrease of fatigue damage, and secondly as a gradual removal of the hole itself by ingrowth of new bone. If the stress concentration was not too severe, or the applied loading (determined by the person's exercise level) was not too great, then the local damage parameter could be seen to pass through a maximum value and thereafter decrease to a constant, non-zero value as the rates of damage and repair became matched. Damage mechanics approaches have also been applied to self-healing engineering materials, for example Liang et al modelled concrete in this way ${ }^{56}$.

A useful extension of CDM is to include a probabilistic element, for example using the Weibull approach. Then, under constant loading conditions, the rate of development of damage and the time (or number of cycles) to failure become probabilistic quantities. So a body part such as a human tibia, for example, which experiences different cyclic strains at different locations, can be assessed to give an overall probability of failure as a function of time. The Weibull formulation can be relatively easily modified to include a negative (repair) term; the result will now be the probability that repair will occur faster than 
the damage accumulates, thus preventing total failure. This approach has been applied to consider some problems in the field of sports science ${ }^{57}$ and other fields in which stress fractures of bones occur as a result of excessive exercise or poor bone health ${ }^{58}$.

The above approaches allow predictions to be made under realistic situations of complex load histories applied to real components or body parts, allowing useful estimates of the potential value of selfhealing. They allow us to investigate an important aspect of self-healing materials which is that they are generally less strong that their non-healing counterparts, as a result of the necessity of including nonload-bearing elements such as microcapsules or internal cavities. Though initially weaker, they are able to maintain their reduced strength for longer; this can be quantified and investigated through a damage mechanics model.

Another approach to theoretical modelling is to attempt to capture the actual mechanisms of damage and repair. Such models are invariably quite complex, and the degree of complexity increases considerably when self-healing becomes involved. Recent work often uses the cohesive zone approach to represent microcrack formation and growth, which is a useful simplification of the real process, especially when applied to quasi-brittle materials such as bone, cements or fibre composites ${ }^{59}$. For example figure 9 shows how a cohesive zone model in a finite element analysis can reproduce the well known behaviour of a microcrack in bone. Alsheghri and Abu Al-Rub developed a finite-element based model using this kind of approach to simulate self-healing in polymers ${ }^{60}$ which was capable of capturing the effects of various parameters including the past history of damage and repair in the material. Another approach which has been applied to bone is to use fracture mechanics theory to predict crack growth rates, incorporating terms to describe the initiation of microcracks and their early growth, which involves a period in which growth rates decrease to a minimum value. Repair was modelled either as a negative growth term or (more realistically given the BMU mechanism described above) a scenario in which the microcrack is removed after a certain period of time, provided it has not grown too large for the repair mechanism to cope with ${ }^{61}$. Experimental studies which record data about the entire population of microcracks in a sample of material (e.g ${ }^{62}$ ) can provide useful input to allow such models to be validated.

It is fair to say that the development of theoretical models and computer simulations of self-healing materials is a subject which is still in its infancy, and which has considerable potential for future development, given the availability of high-power computation. It would be very interesting in this regard to make use of control theory, which has been developed to model the dynamics of systems containing feedback loops, involving sensors and actuators. The application of control theory may allow some of the above modelling approaches to be implemented more efficiently in the form of computer simulations.

\section{Opportunities for biomimetics}

Is there a role for biomimetics in this field? Can an understanding of self-healing phenomena in Nature help in any way when it comes to developing self-healing engineering materials? A number of research groups are actively considering this question and developing bioinspired solutions (see for example the work of Speck and co-workers on plant materials and structures ${ }^{1}$ ).

In a general sense, it is certainly useful to note some features of self-repair which are probably universal. Firstly, the damage must be detected, implying the presence of some kind of sensing system, whether passive or active. The resolution of this system - how small a microcrack can be detected - will depend 
on the fracture characteristics of the material. As noted above, the ideal resolution will correspond to the length which microcracks reach when they undergo a local minimum in growth rates, as the crack interacts with features in the material, such as grain boundaries or bridging ligaments. A useful guide to this dimension is the so-called 'critical distance', L, which can be estimated from other material properties $^{63}$.

Secondly, the necessary materials for carrying out the repair must travel to the site of the damage. This governs the spacing and properties of their sources, for example microcapsules in a polymer resin. In this case the viscosity and diffusivity of the reactive materials will also be important. In bone, the relatively slow speed of movement of the resorption cavity (BMU) is a significant limiting factor.

Thirdly, a chemical reaction must occur at the damage site to create new material. In Nature, the material when first made may be identical to the original material: this happens for example in the repair of microdamage in bone. However in other cases a temporary material may be created, as in the clotting reaction mentioned above, which is then gradually replaced in a slower, remodelling operation.

Systems which clearly display a similarity to natural ones are those which use a so-called vascular architecture. These have been created for polymer, composite and ceramic materials. A number of approaches have been used. For example self-repairing polymers have been created which, instead of using microcapsules filled with monomer, employ a network of thin glass tubes. The catalyst necessary for polymerisation can also be introduced via a second set of tubes. These tubes may have some reinforcing effect on the polymer, but it's likely that their net effect will be to reduce strength. Recently various other approaches have been used to create inbuilt vascular-type systems, which have achieved impressive levels of damage reduction and life extension ${ }^{64,65}$. See for example figure 10 showing repair in a vascular-type structure incorporated into a fibre reinforced polymer. Taking the biological analogy further, it might be possible, via these vascular systems, to continue to introduce more monomer material, thereby avoiding the loss of self-healing capability over time.

Other workers have created a detection system which has similarities to the cellular networks in natural materials: they introduced carbon nanotubes and made use of their electrical properties to detect damage in conventional fibre composites ${ }^{66}$. Another interesting approach which has similarities with natural systems, is the introduction into cements of bacteria capable of producing calcium carbonate, a material which is very commonly synthesised by a whole range of organisms, found in sea shells, birds' eggs etc (see above). Bacteria have been introduced into cement at the manufacturing stage, remaining dormant until exposed to air as a result of cracking. The challenge in this case is to keep the bacteria alive and responsive for long periods of time until they are needed ${ }^{67}$.

However, an important lesson to be learnt from the history of biomimetics is that success is not always achieved by directly copying Nature's solutions. Birds may act as an inspiration to the development of flying machines, but early aircraft could only be developed by taking a distinctly different path, separating the source of the power from the source of lift, leading to a machine with fixed wings and a propeller, rather than trying to copy the complex motions of birds' wings. Rather than attempting to copy the complex cell-signalling systems used by bone cells, we might take a different route: for example recent work has shown that it may be possible to detect the presence of areas of microscopic damage by careful examination of the macroscopic strain field ${ }^{68}$. 


\section{Conclusions}

1. Natural materials are capable of continuously repairing damage thanks to networks of cells which detect microcracks and specialised cells capable of replacing old material with new. An active vascular system is essential to maintain the functions of these detection and production systems.

2. Engineering materials have been designed to have self-healing capability; this is a rapidly expanding field of interest involving all classes of materials. Some of these require a separate healing period involving, for example, heating. Others are capable of continuous self repair but these tend to lose this facility over time.

3. Theoretical models have been developed to explore both natural and artificial self-healing materials. Established approaches such as continuum damage mechanics and cohesive zone models can be used, suitably modified to take account of repair processes. There is scope for considerable further development in this field, for example using control theory.

4. A key parameter for any self-repairing system is the spacing of detectors, which should coincide with the length at which microcracks experience a growth rate minimum, a function of microstructure which is sometimes known as the critical distance. Another important parameter is the rate at which the repair process can act, normally limited by the supply of constituent materials to the damage site.

5. A biomimetic approach, in which we seek inspiration from natural materials, is useful in this field. This has led to the development of fibre composites with simulated vascular structures to allow detection and repair of damage, and other approaches including the use of living cells in the form of bacteria.

\section{Figure Captions}

Figure 1: (a) A fracture surface showing repair of damage in the leg of an insect ${ }^{13}$. The leg was cut using a sharp blade: the cut surface is still visible towards the top. Material formed below the cut to create a patch (here it has been artificially coloured pink), which subsequently fractured when the leg was tested to failure. (b) A magnified view showing part of the cut surface and the patch.

Figure 2: Examples of damage and repair in molluscs. (a) Impact damage created a hole in the shell of this limpet, which has been repaired by patch formation (previously unpublished photograph). (b) repair of a crack in the shell of a bivalve (photographed from both sides), showing how the new patch material formed underneath the cracked area ${ }^{16}$.

Figure 3: (a) An optical micrograph of a cross section of bone (adapted from ${ }^{40}$ ) showing a microscopic crack and a BMU just about to repair the cracked area. The white dots in this picture are osteocyte cells and the white lines are cellular processes forming a network between the cells. (b) An optical micrograph of a cross section through a bone, showing a microcrack (labelled C) and a region of remodelling which has created a secondary osteon (labelled O, diameter approximately 200 microns) ${ }^{21}$

Figure 4: Results from Kennedy et $a{ }^{35}$ showing changes in osteocyte activity as a function of distance from microcracks in the bone of a rat: results from samples which have been fatigued to create damage, compared to undamaged controls. The local increase in RANKL and decrease in OPG indicates that the cells are signalling the presence of the damage. The increase in Caspase 3 indicates that some of the cells near the damage have undergone apoptosis. 
Figure 5: Previously unpublished results from our laboratory ${ }^{39}$, showing changes in osteocyte activity from networks of cells cultured in vitro and damaged by introducing damage in the form of scribed lines of different widths. On each plot the factor of increase (compared to undamaged controls) is plotted on the vertical axis. Each data point represents a minimum of 3 test samples: solid points indicate a statistically significant difference compared to the control (ANOVA, $p<0.05$ ). (a) RANKL increases with the severity of the damage (defect width); it is significantly elevated above control levels even for narrow, crack-like defects, especially at distances close to the defect (0-200microns). (b) OPG levels decrease dramatically one day after damage, for both narrow and wide defects. (c) The RANKL/OPG ratio, which is crucial for the stimulation of repair, rises rapidly with time for both narrow and wide defects, but declines after three days in the narrow, crack like defect as it is repaired by cell migration. (d) Apoptosis is elevated close to (but not further away from) the site of damage, for all types of defect.

Figure 6: Scanning electron microscope image of part of a crack in a bone sample showing two cellular processes crossing the crack, one of which is still intact whilst the other has broken by fatigue as a result of applied cyclic loads ${ }^{41}$.

Figure 7: Results from Zhang et $a l^{52}$ showing gold-based precipitates forming on strain-induced defects in a ferrous alloy: the arrows indicate precipitates on dislocations.

Figure 8: (a) A schematic showing the principle of self-healing in polymers using microcapsules. (b) A time sequence showing rupture of a microcapsule, releasing the healing agent ${ }^{53}$.

Figure 9: Results from a computer simulation by Mischinski et al ${ }^{59}$ showing a commonly observed phenomenon in bone, whereby a microcrack, on reaching the boundary of an osteon, may either pass through it or divert around it. These workers used a cohesive zone model with a finite element analysis.

Figure 10: Norris et $a l^{64}$ developed a vascular-type structure to deliver healing agents in a fibre reinforced polymer. As the results show, samples damaged at different applied stresses were able to recover almost all their original strength.

References

1. Speck O \& Speck T (2015). Self-repair in nature and technology: Seal, heal, repair. Biologie in Unserer Zeit 45, 44-51.

2. Currey J Bones: Structure and Mechanics (2002). Princeton University Press, USA.

3. Taylor D \& Dirks J H (2012). Shape optimization in exoskeletons and endoskeletons: A biomechanics analysis. Journal of the Royal Society Interface 9, 3480-3489.

4. Taylor D (2008). Bone as a structural material: how good is it? Studies in Health Technology and Informatics 133, 221-229. 
5. Taylor D, Walsh M, Cullen A. \& O'Reilly P (2016). The fracture toughness of eggshell. Acta Biomaterialia 37, 21-27.

6. Barthelat F, Tang H, Zavattieri P D, Li C M \& Espinosa H D (2007). On the mechanics of mother-ofpearl: A key feature in the material hierarchical structure. Journal of the Mechanics and Physics of Solids 55, 306-337.

7. Nalla R K, Kruzic J J, Kinney J H \& Ritchie R O (2004). Effect of aging on the toughness of human cortical bone: Evaluation by R-curves. Bone 35, 1240-1246.

8. Zimmermann E A \& Ritchie R O (2015). Bone as a Structural Material. Advanced Healthcare Materials 4, 1287-1304.

9. Zhang H, Shen P, Shaga A, Guo R. \& Jiang Q (2016). Preparation of nacre-like composites by reactive infiltration of a magnesium alloy into porous silicon carbide derived from ice template. Materials Letters 183, 299-302.

10. Wigglesworth $\vee B$ (1937). Wound healing in an insect (Rhodnius proxilus hemiptera). Journal of Experimental Biology 14, 364-381.

11. Lai-Fook J (1968). The fine structure of wound repair in an insect (Rhodnius prolixus). Journal of Morphology 124, 37-78.

12. Lai-Fook J (1970). Haemocytes in the repair of wounds in an insect (Rhodnius prolixus). Journal of Morphology 130, 297-313.

13. Parle E, Dirks J H \& Taylor D (2016). Bridging the gap: Wound healing in insects restores mechanical strength by targeted cuticle deposition. Journal of the Royal Society Interface 13, article number 20150984 .

14. Shanks A L \& Wright W G (1986). Adding teeth to wave action: the destructive effects of waveborne rocks on intertidal organisms. Oecologia 69, 420-428.

15. Cadee G C (1999). Shell damage and shell repair in the Antarctic limpet Nacella concinna from King George Island. Journal of Sea Research 41, 149-161.

16. Harper E M, Clark M S, Hoffman J I, Philipp E E R, Peck L S and Morley S A (2012). Iceberg Scour and Shell Damage in the Antarctic Bivalve Laternula elliptica. PLOS ONE 7, e46341.

17. Blundon J A \& Vermeij G J (1983). Effect of shell repair on shell strength in the gastropod Littorina irrorata. Marine Biology 76, 41-45.

18. Ulstrup K A (2008). Biomechanical concepts of fracture healing in weight-bearing long bones. Acta Orthopedica Belgica 74, 291-302.

19. Frost H M (1960). Presence of microscopic cracks in vivo in bone. Henry Ford Hosp Med Bull 8, 2535. 
20. Taylor D \& Lee T C (1998). Measuring the shape and size of microcracks in bone. Journal of Biomechanics 31, 1177-1180.

21. O'Brien F J, Taylor D \& Lee T C (2003). Microcrack accumulation at different intervals during fatigue testing of compact bone. Journal of Biomechanics 36, 973-980.

22. Taylor D, Hazenberg J G \& Lee T C (2007). Living with Cracks: Damage and Repair in Human Bone. Nature Materials 2, 263-268.

23. Allen M R \& Burr D B (2008). Skeletal microdamage: Less about biomechanics and more about remodeling. Clinical Reviews in Bone and Mineral Metabolism 6, 24-30.

24. Burr D B (2002). Targeted and nontargeted remodeling. Bone 30, 2-4.

25. Busse B, Djonic D, Milovanovic P, Hahn M, Puschel K, Ritchie R O, Djuric M \& Amling M (2010). Decrease in the osteocyte lacunar density accompanied by hypermineralized lacunar occlusion reveals failure and delay of remodeling in aged human bone. Aging Cell 9, 1065-1075 (2010).

26. Vom Scheidt A \& Busse B (2016). Characteristics of the osteocyte network in healthy and diseased human bone. Osteologie 25, 69-76.

27. Taylor D (2011). What we can't learn from nature. Materials Science and Engineering C 31, 11601163.

28. Wang L. et al (2014). Repair of microdamage in osteonal cortical bone adjacent to bone screw. PLOS ONE 9.

29. O'Brien F J, Taylor D \& Lee T C (2005). The effect of bone microstructure on the initiation and growth of microcracks. Journal of Orthopaedic Research 23, 475-480.

30. Lin Z X, Xu Z H, An Y H \& Li X (2016). In situ observation of fracture behavior of canine cortical bone under bending. Materials Science and Engineering C 62, 361-367.

31. Akkus O \& Rimnac C M (2001). Cortical bone tissue resists fatigue fracture by deceleration and arrest of microcrack growth. Journal of Biomechanics 34, 757-764.

32. Mullender M G, Huiskes R, Versleyen H \& Buma P (1996). Osteocyte density and histomorphometric parameters in cancellous bone of the proximal femur in five mammalian species. Journal of Orthopaedic Research 14, 972-979.

33. Schneider P, Meier M, Wepf R \& Muller R (2010). Towards quantitative 3D imaging of the osteocyte lacuno-canalicular network. Bone 47, 848-858.

34. Milovanovic P. et al (2013). Osteocytic canalicular networks: Morphological implications for altered mechanosensitivity. ACS Nano 7, 7542-7551.

35. Kennedy O D, Herman B C, Laudier D M, Majeska R J, Sun H B \& Schaffler M B (2012). Activation of resorption in fatigue-loaded bone involves both apoptosis and active pro-osteoclastogenic signaling by distinct osteocyte populations. Bone 50, 1115-1122. 
36. Kennedy O D, Laudier D M, Majeska R J, Sun H B \& Schaffler M B (2014). Osteocyte apoptosis is required for production of osteoclastogenic signals following bone fatigue in vivo. Bone 64, 132137.

37. Mulcahy LE, Taylor D, Lee T C \& Duffy G P (2011). RANKL and OPG activity is regulated by injury size in networks of osteocyte-like cells. Bone 48, 182-188.

38. Mulcahy L E, Curtin C M, McCoy R J, Taylor D, Lee T C and Duffy G P (2015). The effect of bisphosphonate treatment on the biochemical and cellular events during bone remodelling in response to microinjury stimulation. European Cells and Materials 30, 271-281.

39. Dooley C (2013). Targeted Bone Remodelling: Investigating the Scissors Model. PhD thesis. Trinity College Dublin, The University of Dublin.

40. Colopy S A, Benz-Dean J, Barrett J G, Sample S J, Lu Y, Danova N A, Kalscheur V L, Vanderby R, Markel M D \& Muir P (2004). Response of the osteocyte syncytium adjacent to and distant from linear microcracks during adaptation to cyclic fatigue loading. Bone 35, 881-891.

41. Dooley C, TisboP, Lee T C \& Taylor D (2012). Rupture of osteocyte processes across microcracks: The effect of crack length and stress. Biomechanics and Modeling in Mechanobiology 11, 759-766.

42. Dooley C, Cafferky D, Lee T C \& Taylor D (2014). Fatigue failure of osteocyte cellular processes: implications for the repair of bone. European Cells and Materials 27, 39-49.

43. Mofrad R K \& Kamm R D (2010). Cellular Mechanotransduction. Cambridge University Press, Cambridge, UK.

44. Liu C, Zhang X, Wu M \& You L (2015). Mechanical loading up-regulates early remodeling signals from osteocytes subjected to physical damage. Journal of Biomechanics 48, 4221-4228.

45. Shu Y. et al (2014). Surface microcracks signal osteoblasts to regulate alignment and bone formation. Materials Science and Engineering C 44, 191-200.

46. Jung $\mathrm{H}$, Best $\mathrm{M}$ \& Akkus $\mathrm{O}$ (2015). Microdamage induced calcium efflux from bone matrix activates intracellular calcium signaling in osteoblasts via L-type and T-type voltage-gated calcium channels. Bone 76, 88-96 (2015).

47. deRooij M, Van Tittleboom M, De Belie N. \& Schlangen E (2013). Self-Healing Phenomena in Cement-Based Materials. Springer.

48. Mazzoni G, Stimilli A \& Canestrari F (2016). Self-healing capability and thixotropy of bituminous mastics. International Journal of Fatigue 92, 8-17.

49. Hosoi A, Yano T, Morita Y \& Ju Y (2014). Quantitative evaluation of the displacement distribution and stress intensity factor of fatigue cracks healed by a controlled high-density electric current field. Fatigue and Fracture of Engineering Materials and Structures 37, 1025-1033. 
50. Ando K, Chu M C, Yao F \& Sato S (1999). Fatigue strength of crack-healed Si3N4/SiC composite ceramics. Fatigue and Fracture of Engineering Materials and Structures 22, 897-903.

51. Liu S P, Ando K, Kim B S \& Takahashi K (2009). In situ crack-healing behavior of Al2O3/SiC composite ceramics undercyclic-fatigue strength. International Communications in Heat and Mass Transfer 36, 558-562.

52. Zhang S, Kohlbrecher J, Tichelaar F D, Langelaan G, Bruck E, van der Zwaag S, \& van Dijk N H (2013). Defect-induced Au precipitation in Fe-Au and Fe-Au-B-N alloys studied by in situ smallangle neutron scattering. Acta Materialia 61, 7009-7019.

53. White S R, Sottos N R, Geubelle P H, Moore J S, Kessler M R, Sriram S R, Brown E N \& Viswanathan $S$ (2001). Autonomic healing of polymer composites. Nature 409, 794-797.

54. Cho S H, White S R \& Braun P V (2012). Room-temperature polydimethylsiloxane-based selfhealing polymers. Chemistry of Materials 24, 4209-4214.

55. Brazel E \& Taylor D (2009). Predicting the structural integrity of bone defects repaired using bone graft materials. Computer methods in Biomechanics and Biomedical Engineering 12, 297-304.

56. Liang J, Ren X \& Li J (2016). A competitive mechanism driven damage-plasticity model for fatigue behavior of concrete. International Journal of Damage Mechanics 25, 377-399.

57. Edwards W B, Taylor D, Rudolphi T J, Gillette J C \& Derrick T R (2009). Effects of stride length and running mileage on a probabilistic stress fracture model. Medicine and Science in Sports and Exercise 41, 2177-2184 (2009).

58. Taylor D, Casolari E \& Bignardi C (2004). Predicting stress fractures using a probabilistic model of damage, repair and adaptation. Journal of Orthopaedic Research 22, 487-494 (2004).

59. Mischinski ,S \& Ural A (2011). Finite element modeling of microcrack growth in cortical bone. Journal of Applied Mechanics, Trans ASME 78, 041016.

60. Alsheghri A A \& Abu Al-Rub R K (2016). Finite element implementation and application of a cohesive zone damage-healing model for self-healing materials. Engineering Fracture Mechanics 163, 1-22.

61. Taylor D, O'Brien F \& Lee T C (2002). A theoretical model for the simulation of microdamage accumulation and repair in compact bone. Meccanica 37, 397-406 .

62. Presbitero G, O'Brien F J, Lee T C \& Taylor D (2012). Distribution of microcrack lengths in bone in vivo and in vitro. Journal of Theoretical Biology 304, 164-171.

63. Taylor D (2007). The Theory of Critical Distances: A New Perspective in Fracture Mechanics. Elsevier, Oxford, UK.

64. Norris C J, Meadway G J, O'Sullivan M J, Bond I P \& Trask R S (2011). Self-healing fibre reinforced composites via a bioinspired vasculature. Advanced Functional Materials 21, 3624-3633. 
65. Lee M W, Sett S, Yoon S S, \& Yarin A L (2016). Fatigue of Self-Healing Nanofiber-based Composites: Static Test and Subcritical Crack Propagation. ACS Applied Materials and Interfaces 8, 1846218470.

66. Thostenson E T \& Chou T W (2006). Carbon nanotube networks: Sensing of distributed strain and damage for life prediction and self healing. Advanced Materials 18, 2837-2841.

67. Wang J, Van Tittelboom K, De Belie N \& Verstraete W (2012). Use of silica gel or polyurethane immobilized bacteria for self-healing concrete. Construction and Building Materials 26, 532-540.

68. Das S \& Chakravarty S (2013). Characterization of micro-anomalies from macro-scale response. 2013. 54th AIAA/ASME/ASCE/AHS/ASC Structures, Structural Dynamics and Materials Conference, $8^{\text {th }}$ January, Boston, USA. 

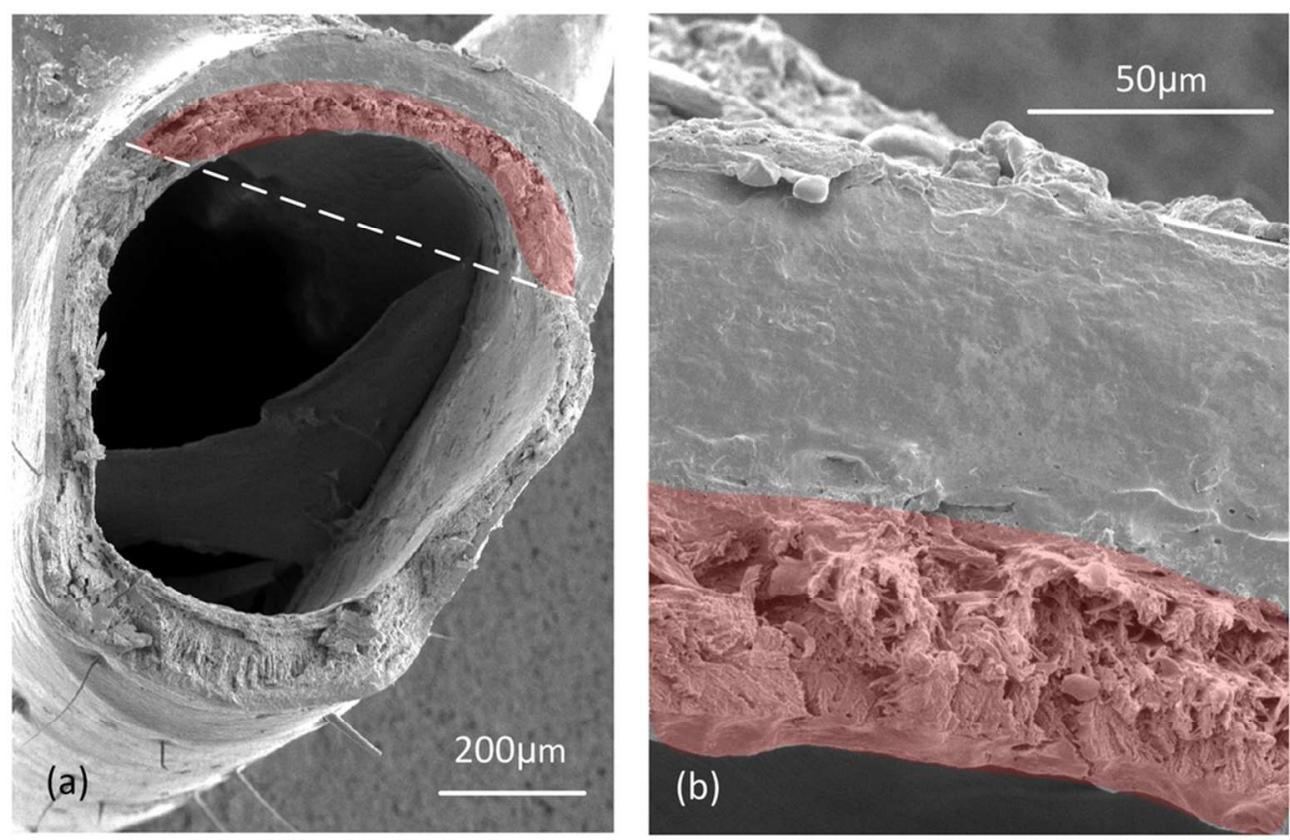

Figure 1: A fracture surface showing repair of damage in the leg of an insect (10). The leg was cut using a sharp blade: the cut surface is still visible towards the top. Material formed below the cut to create a patch (here it has been artificially coloured pink), which subsequently fractured when the leg was tested to failure.

$$
89 \times 59 \mathrm{~mm}(300 \times 300 \mathrm{DPI})
$$


Figure 2: Examples of damage and repair in molluscs. (a) Impact damage created a hole in the shell of this limpet, which has been repaired by patch formation (previously unpublished photograph). (b) repair of a crack in the shell of a bivalve, showing how the new patch material formed underneath the cracked area (13).

$129 \times 99 \mathrm{~mm}(300 \times 300$ DPI $)$ 

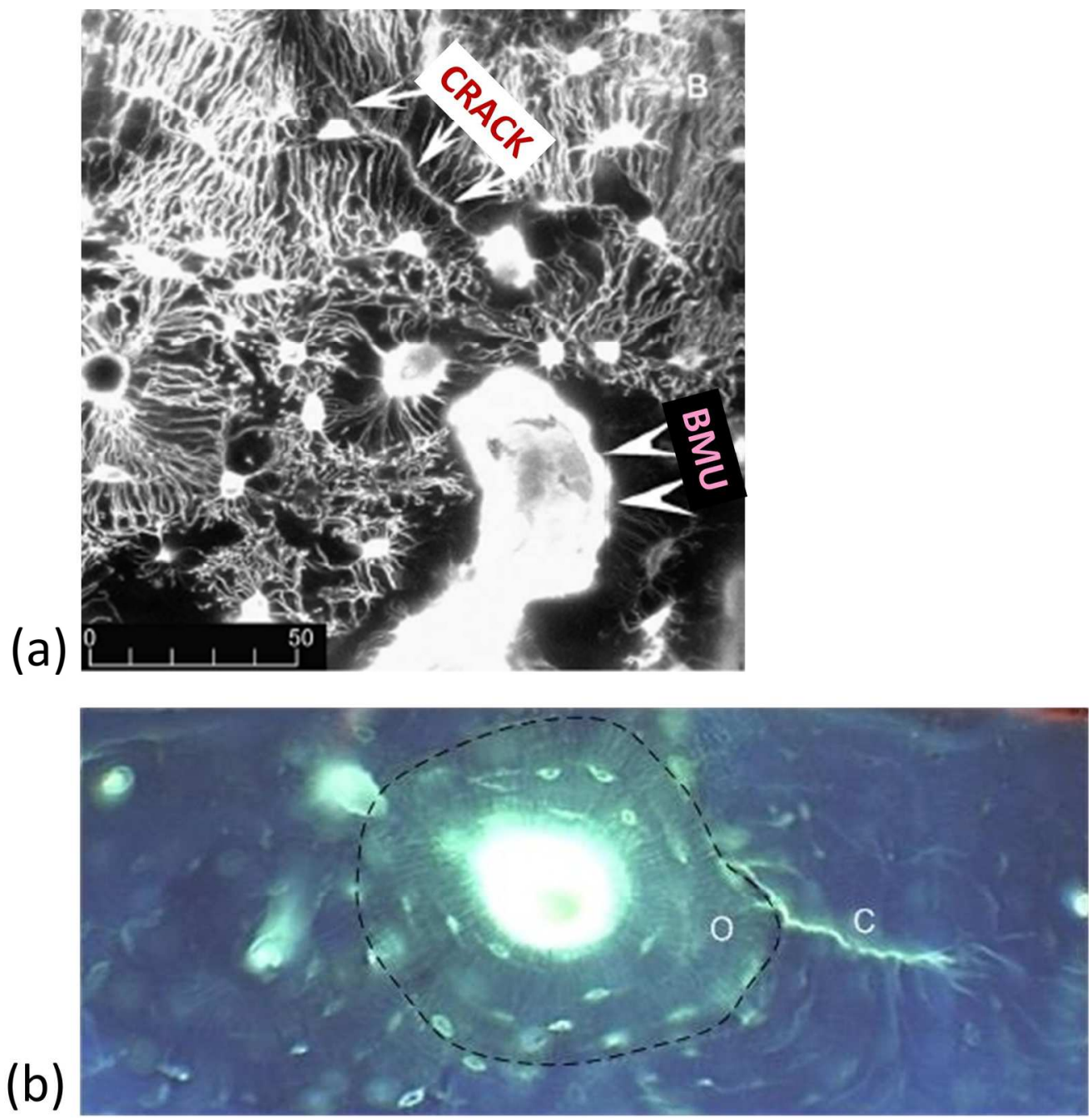

Figure 3: (a) An optical micrograph of a cross section of bone (adapted from 40) showing a microscopic crack and a BMU just about to repair the cracked area. The white dots in this picture are osteocyte cells and the white lines are cellular processes forming a network between the cells. (b) An optical micrograph of a cross section through a bone, showing a microcrack (labelled $\mathrm{C}$ ) and a region of remodelling which has created a secondary osteon (labelled O, diameter approximately 200 microns) 21

$171 \times 175 \mathrm{~mm}(300 \times 300 \mathrm{DPI})$ 

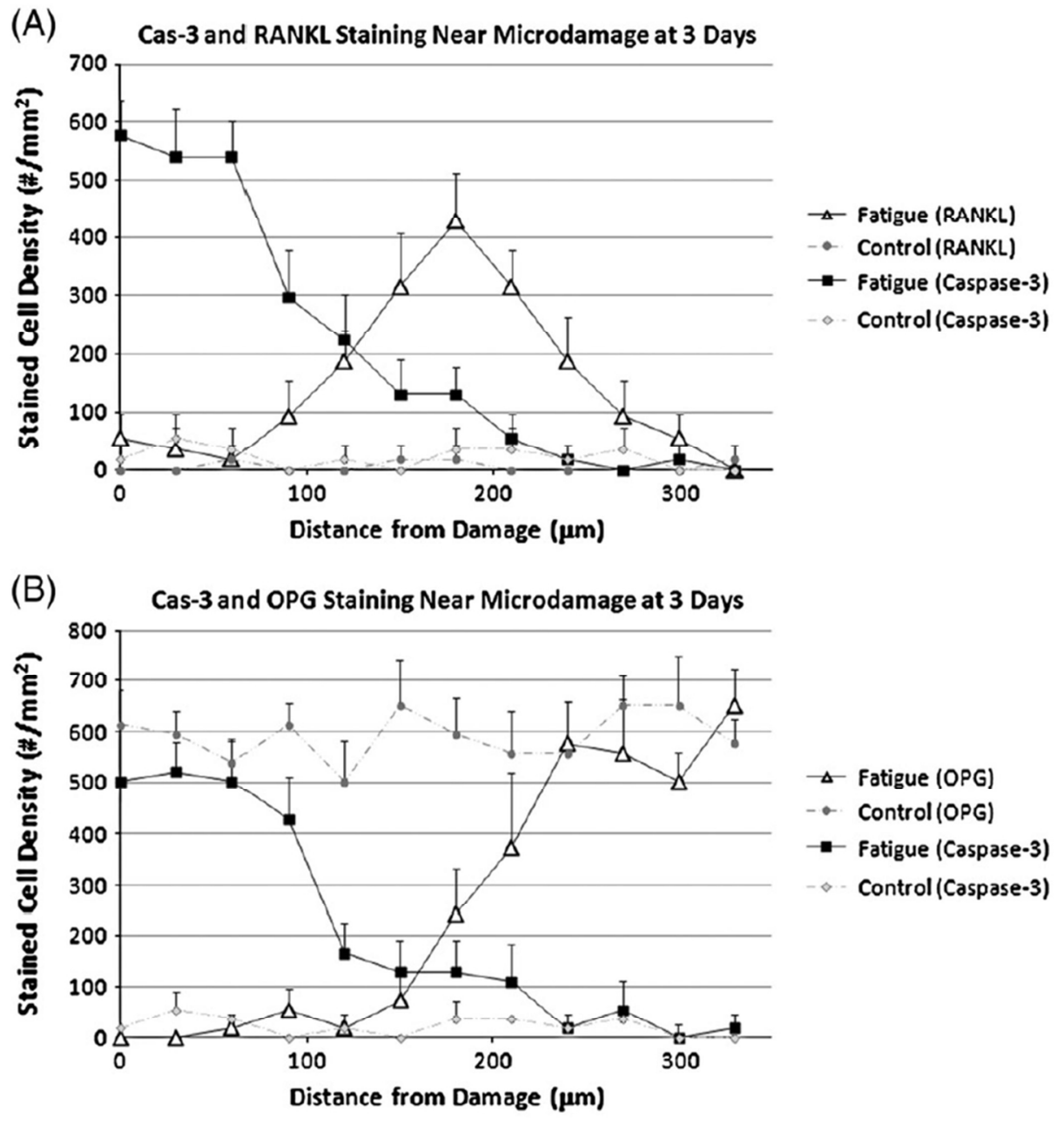

Figure 4: Results from Kennedy et al (32) showing changes in osteocyte activity as a function of distance from microcracks in the bone of a rat: results from samples which have been fatigued to create damage, compared to undamaged controls. The local increase in RANKL and decrease in OPG indicates that the cells are signalling the presence of the damage. The increase in Caspase 3 indicates that some of the cells near the damage have undergone apoptosis.

$115 \times 116 \mathrm{~mm}(300 \times 300 \mathrm{DPI})$ 
(a)

RANKL

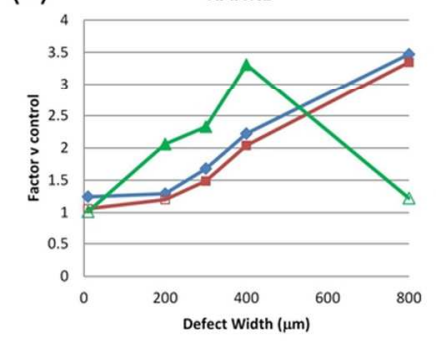

$\rightarrow-0-200 u m ; 5-45 \mathrm{mins}$ $\rightarrow-200-300 \mathrm{um} ; 5.45 \mathrm{mins}$ $\rightarrow-0-200 u m$; 3days

(c)

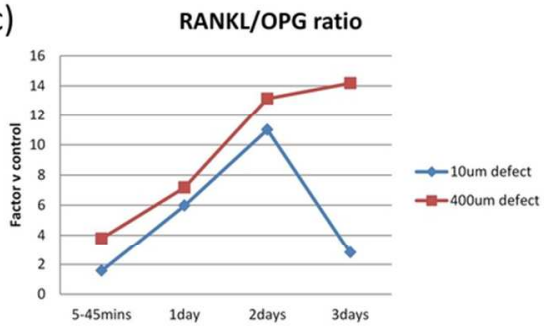

(b)

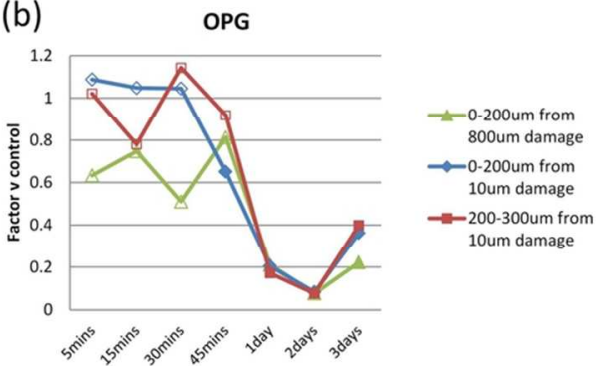

(d) Apoptosis: 3 days

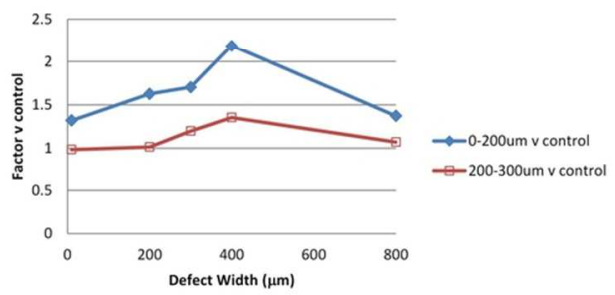

Figure 5: Previously unpublished results from our laboratory, showing changes in osteocyte activity from networks of cells cultured in vitro and damaged by introducing slots of different widths. (a) RANKL increases with the severity of the damage (defect width); it is significantly elevated above control levels even for narrow, crack-like defects, especially at distances close to the defect (0-200microns). (b) OPG levels decrease dramatically one day after damage, for both narrow and wide defects. (c) The RANKL/OPG ratio, which is crucial for the stimulation of repair, rises rapidly with time for both narrow and wide defects, but declines after three days in the narrow, crack like defect as it is repaired. (d) Apoptosis is elevated close to (but not further away from) the site of damage, for all types of defect.

$89 \times 53 \mathrm{~mm}(300 \times 300 \mathrm{DPI})$ 
Figure 6: Scanning electron microscope image of part of a crack in a bone sample showing two cellular processes crossing the crack, one of which is still intact whilst the other has broken by fatigue as a result of applied cyclic loads (37).

$126 \times 104 \mathrm{~mm}(300 \times 300$ DPI $)$ 

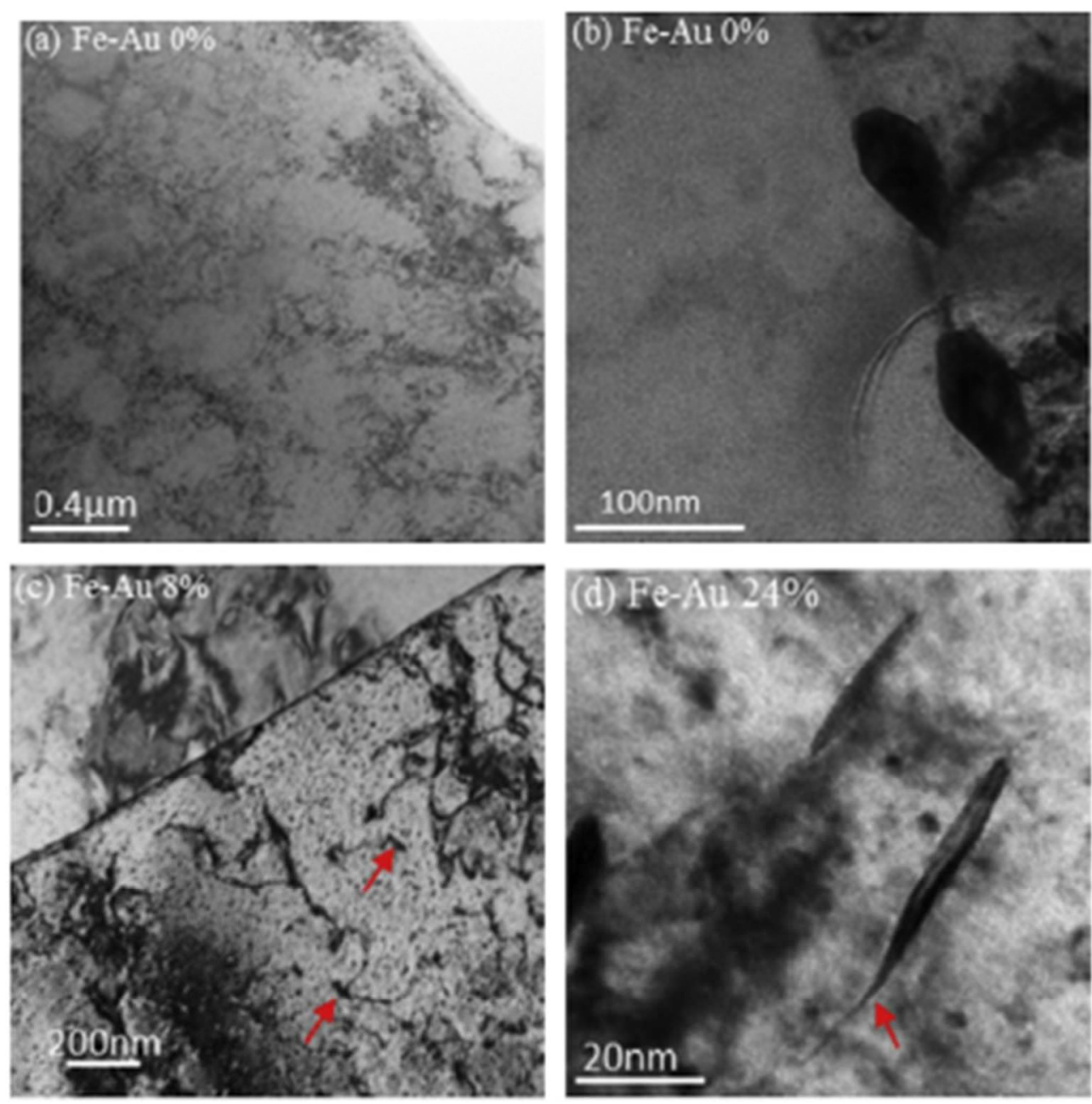

Figure 7: Results from Zhang et al (47) showing gold-based precipitates forming on strain-induced defects in a ferrous alloy.

$134 \times 134 \mathrm{~mm}(300 \times 300 \mathrm{DPI})$ 

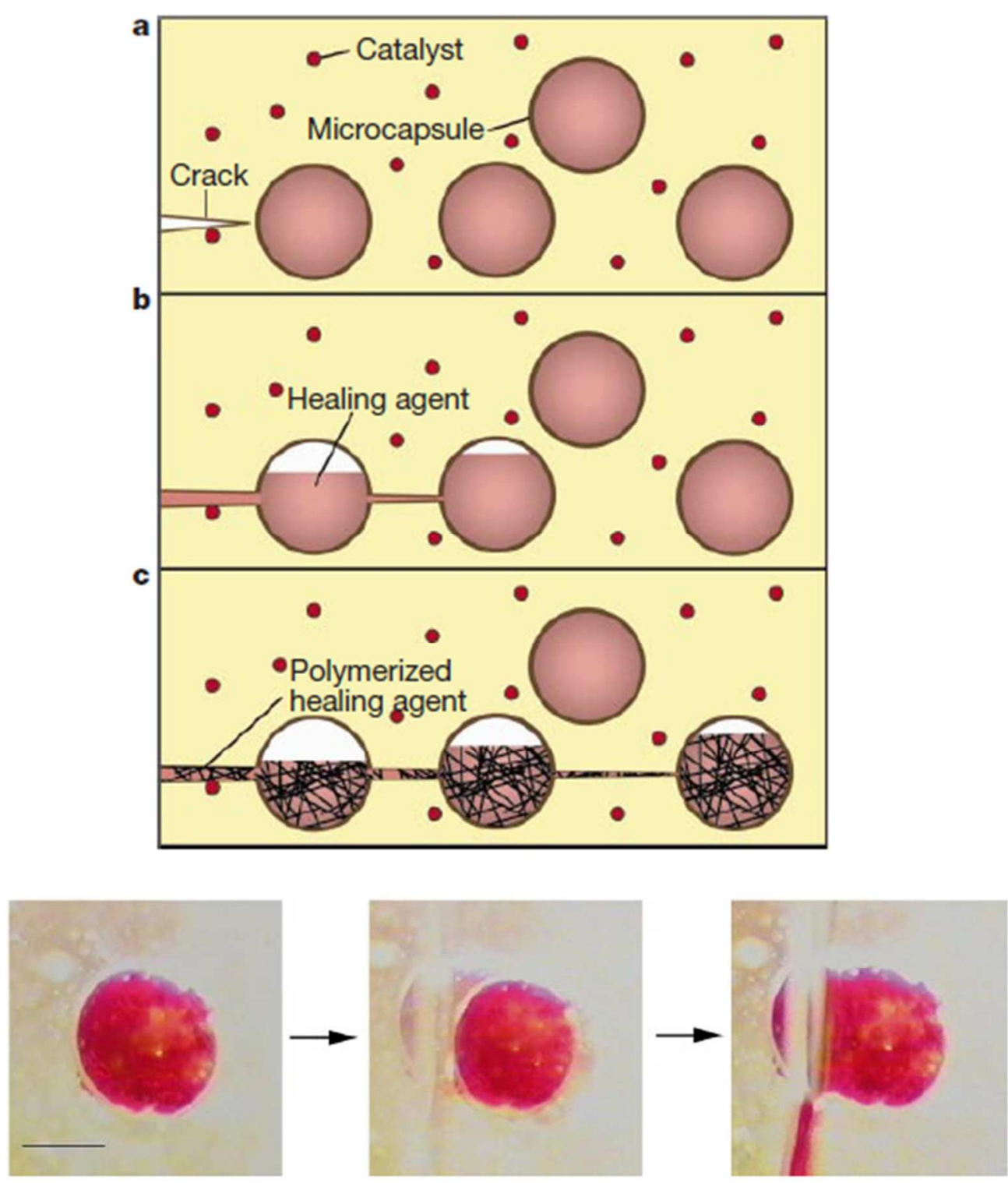

Figure 8: (a) A schematic showing the principle of self-healing in polymers using microcapsules. (b) A time sequence showing rupture of a microcapsule, releasing the healing agent (48).

$$
210 \times 247 \mathrm{~mm}(300 \times 300 \mathrm{DPI})
$$


(a)

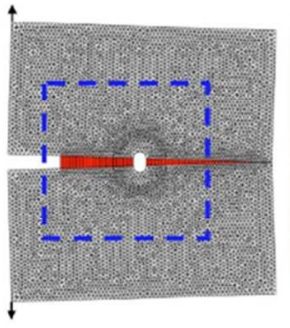

(b)

(c)

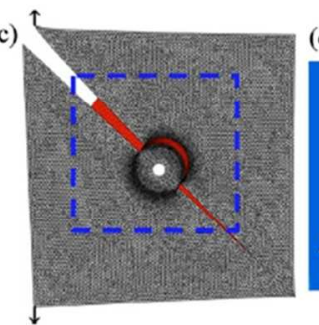

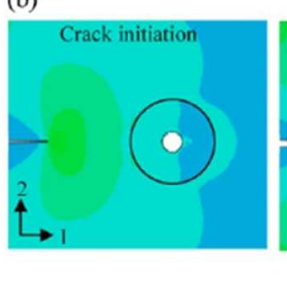
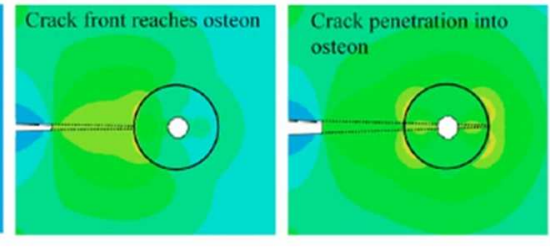

$\sigma_{22}$

$100 \mathrm{MPa}$

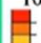

- $35 \mathrm{MPa}$

$-10 \mathrm{MPa}$
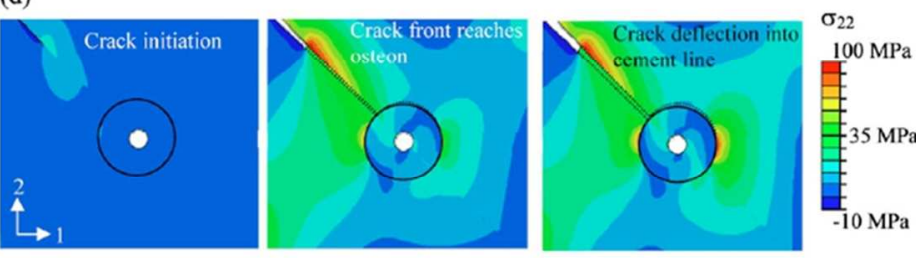

Figure 9: Results from a computer simulation by Mischinski et al (54) showing a commonly observed phenomenon in bone, whereby a microcrack, on reaching the boundary of an osteon, may either pass through it or divert around it. These workers used a cohesive zone model with a finite element analysis.

$96 \times 51 \mathrm{~mm}(300 \times 300$ DPI $)$ 

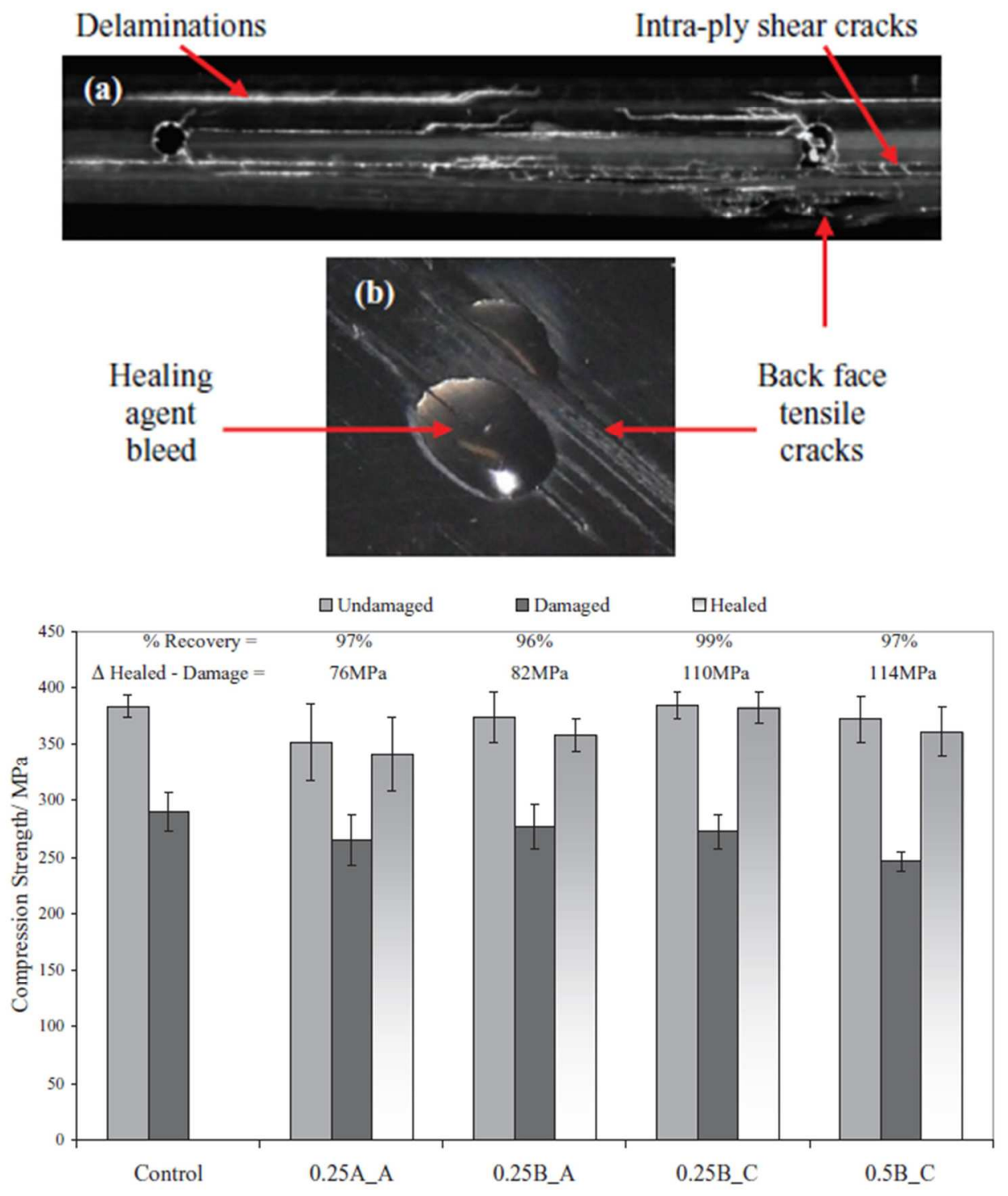

Figure 10: Norris et al (59) developed a vascular-type structure to deliver healing agents in a fibre reinforced polymer. As the results show, samples damaged at different applied stresses were able to recover almost all their original strength.

$$
204 \times 232 \mathrm{~mm} \text { ( } 300 \times 300 \text { DPI) }
$$

